\title{
Antimicrobial peptides in innate intestinal host defence
}

Wilson CL, Ouellette AJ, Satchell DP, et al. Regulation of intestinal $\alpha$-defensin activation by the metalloproteinase matrilysin in innate host defence. Science 1999;286:113-17.

\section{Abstract}

Precursors of alpha-defensin peptides require activation for bactericidal activity. In mouse small intestine, matrilysin colocalized with alpha-defensins (cryptdins) in Paneth cell granules, and in vitro it cleaved the pro segment from cryptdin precursors. Matrilysin-deficient (MAT-I-) mice lacked mature cryptdins and accumulated precursor molecules. Intestinal peptide preparations from MAT-I- mice had decreased antimicrobial activity. Orally administered bacteria survived in greater numbers and were more virulent in MAT-Imice than in MAT $+/+$ mice. Thus, matrilysin functions in intestinal mucosal defense by regulating the activity of defensins, which may be a common role for this metalloproteinase in its numerous epithelial sites of expression.

\section{Comment}

Following two recent review articles, ${ }^{12}$ readers of Gut will be aware of the increasing interest in the role of antimicrobial peptides in innate intestinal host defence.

Antimicrobial peptides of the defensin family were first isolated from neutrophils and macrophages in the 1980s and the expression of members of this family (designated cryptdins) in murine Paneth cells was subsequently reported..$^{3-5}$ Based on the organisation of their disulphide bonds, the defensin family has been further subdivided into $\alpha$ and $\beta$ defensins, with the human neutrophil defensins 1-4 (HNP 1-4) and murine cryptdins falling into the former group. Previous studies have shown that $\alpha$ defensins are synthesised as biologically inactive precursor molecules that require processing to the mature peptides that express antimicrobial activity. ${ }^{6}$ Normal murine Paneth cells contain mature forms of cryptdin, ${ }^{3-5}$ implying that the enzyme that cleaves the precursor cryptdin isoforms is also present within Paneth cells. This recent study by Wilson and colleagues shows that the matrix metalloproteinase matrilysin (MMP-7) is the enzyme responsible for processing of the precursor forms of murine cryptdins to the active mature peptides. A clue to the potential role of MMP-7 in this function was initially provided by the fact that in the murine small intestine it is expressed in the Paneth cell.

Mice in whom MMP-7 genes were inactivated (MAT-/-) and which therefore did not express MMP-7 enzyme in Paneth cells were studied. Interestingly, in contrast with MMP-7 expressing mice (MAT+/+), the

MMP-7 deficient animals expressed only the precursor forms of cryptdins in their Paneth cells. In vitro studies also showed that MMP-7 cleaves the pro segment from recombinant cryptdin precursors to yield mature peptides with the same N-terminal amino acid sequence as that previously reported for native mature cryptdins isolated from Paneth cells of normal mice.

In functional studies, the antimicrobial activities of intestinal extracts and secreted Paneth cell contents of MAT-/- mice were reduced compared with MAT +/+ mice. Also, following intragastric inoculation of a luminally confined strain of $E$ coli, significantly more of these bacteria were present in the lumen of the distal small bowel of MAT $-/-$ mice compared with their wild-type counterpart $(\mathrm{MAT}+/+)$. Survival after oral challenge with $S$ typhimurium was also greater in MAT $+/+$ than in MAT $-/-$ mice. These functional studies support an important role in vivo of $\alpha$ defensins and MMP-7 in intestinal antimicrobial defence although alternative explanations may also be plausible.

Can these studies be extrapolated to humans? In contrast with the large number of cryptdin isoforms in mice, ${ }^{8}$ only two members of the $\alpha$ defensin family have been found to be expressed in human Paneth cells. ${ }^{2}$ Our recent studies suggest that there may be important differences between mice and humans in the processing of Paneth cell $\alpha$ defensins. Thus we have found that only the precursor form of human defensin 5 (HD-5) is present in normal terminal ileal Paneth cells and that its processing may occur during secretion. ${ }^{9}$

With the recent demonstration of epithelial expression of HNP $1-3$ in inflammatory bowel disease ${ }^{10}$ and of $\beta$ defensins in intestinal epithelial cells, ${ }^{11}{ }^{12}$ defensin mediated innate intestinal host defence is an area of considerable current interest. The paper by Wilson and colleagues makes a major contribution to this field by demonstrating that MMP-7, a member of the matrix metalloproteinase family of enzymes known for its ability to degrade extracellular matrix proteins, regulates activation of $\alpha$ defensins in murine Paneth cells.

R N CUNLIFFE

Alimentary Pharmacology and Therapeutics Trust/Digestive Disorders Foundation Research Training Fellow

Y R MAHIDA

Division of Gastroenterology, University Hospital,

Queen's Medical Centre,

Nottingham NG7 2UH, UK

Email:Yash.Mahida@nottingham.ac.uk

Conflict of interest statement: Professor Mahida is currently collaborating with one of the authors on a research project.

1 Mahida YR, Rose F, Chan WC. Antimicrobial peptides in the gastrointestinal tract. Gut 1997;40:161-3.

2 Bevins CL, Martin-Porter E, Ganz T. Defensins and innate host defence of the gastrointestinal tract. Gut 1999;45:911-15.

3 Ouellette AJ, Greco RM, James M, Frederick D, Naftilan J, Fallon JT. Developmental regulation of cryptdin, a corticostatin/defensin precursor mRNA in mouse small intestinal crypt epithelium. I Cell Biol 1989;108: 1687-95.

4 Selsted ME, Miller SI, Henschen AH, Ouellette AJ. Enteric defensins: antibiotic peptide components of intestinal host defense. F Cell Biol 1992;118: biotic pep

5 Eisenhauer PB, Harwig SSSL, Lehrer RI. Cryptdins: antimicrobial defensins of the murine small intestine. Infect Immun 1992;60:3556-65. 
6 Lehrer RI, Lichtenstein AK, Ganz T. Defensins: antimicrobial and cytotoxic peptides of mammalian cells. Annu Rev Immunol 1993;11:105-28.

7 Wilson CL, Heppner KJ, Rudolph LA, Matrisian LM. The metalloproteinase matrilysin is preferentially expressed by epithelial cells in a tissue restricted pattern in the mouse. Mol Biol Cell 1995;6:851-69.

8 Ouellette AJ, Hsieh MM, Nosek MT, et al. Mouse Paneth cell defensins: primary structures and antibacterial activities of numerous cryptdin isoforms. Infect Immun 1994;62:5040-7.

9 Cunliffe RN, Rose FRAJ, Keyte J, Abberley L, Chan WC, Mahida YR. Isolation and characterisation of human defensin 5 (HD5) from small intestinal Paneth cells. Gut 1999;45(suppl V):A27.
10 Cunliffe RN, Rose FRAJ, James PD, Mahida YR. Expression of antimicrobial neutrophil defensin and lysozyme is induced in epithelial cells of active inflammatory bowel disease (IBD) mucosa. Gastroenterology 1999;116:G3936.

11 Tarver AP, Clark DP, Diamond G, et al. Enteric $\beta$-defensin: molecular cloning and characterisation of a gene with inducible epithelial cell expression associated with Cryptosporidium parvum infection. Infect Immun 1998;66: $1045-56$.

12 O'Neil DA, Porter EM, Elewaut D, et al. Expression and regulation of the human $\beta$-defensins hBD-1 and hBD-2 in intestinal epithelium. $\mathcal{F}$ Immunol 1999;163:6718-24. 